CB)

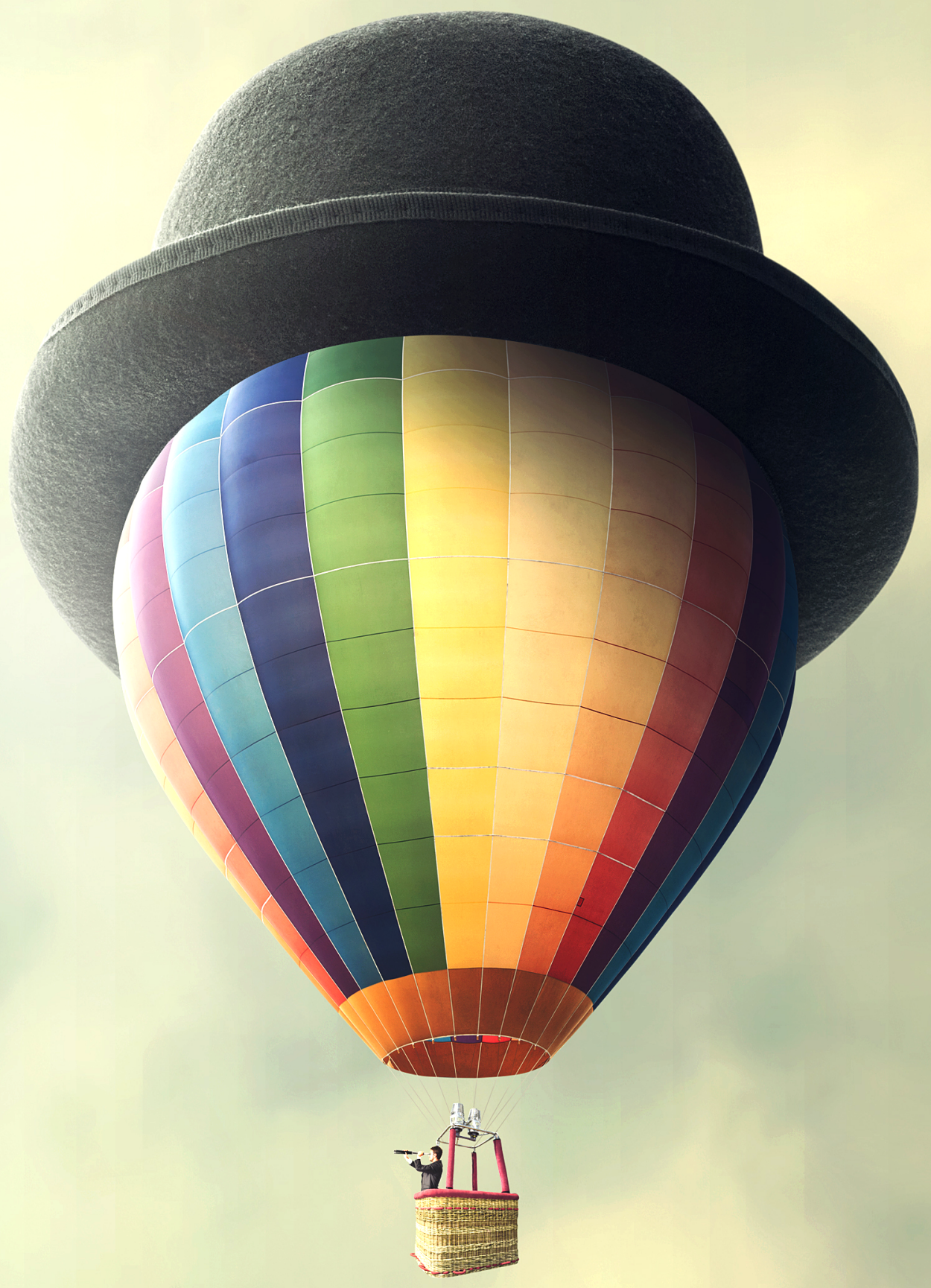




\section{O NEGÓCIO É CRIATIVIDADE}

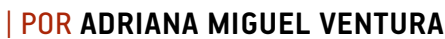

\section{O empreendedor artístico e cultural precisa quebrar a dependência de grandes projetos e verbas de incentivo do modelo atual.}

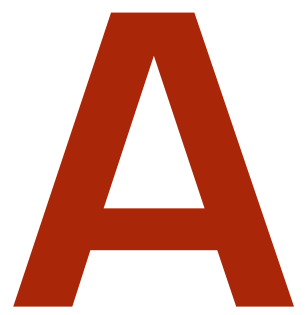

$\mathrm{s}$ atividades culturais e artísticas constituem, atualmente, um dos setores mais dinâmicos da economia mundial. Essas atividades, que formam o setor de indústrias criativas, envolvem artes performáticas, artesanato, gastronomia, design, moda, cinema, softwares, publicidade, arquitetura, museus, rádio e TV, entre outras tantas que têm na criatividade a matéria-prima essencial e intrínseca à produção (ver quadro na página seguinte). Movimentam $5,4 \%$ do produto interno bruto (PIB) do Reino Unido, 3,3\% do PIB dos EUA e 2,6\% do PIB brasileiro, segundo os últimos dados disponíveis, de 2015.

No Brasil, houve forte crescimento das indústrias criativas nos últimos 15 anos. Segundo dados da Federação das Indústrias do Estado do Rio de Janeiro (FIRJAN), o mercado de trabalho do setor cresceu 90\% entre 2004 e 2013 , chegando a 892,5 mil trabalhadores formais em 2014. Essa expansão deve-se a fatores como o aumento da renda (até 2012), o crescimento do turismo, o desenvolvimento tecnológico e o aumento das faculdades e carreiras criativas. Se falarmos especificamente do núcleo da Cultura nas Indústrias Criativas (ver quadro), desde 2006, ocorreu um boom no número de espetáculos e shows, principalmente no eixo São Paulo-Rio de Janeiro.

Com essa expansão, surgiu um novo campo para empreendedores artísticos/culturais. Impulsionados por leis de

\author{
Ainda que possam viabilizar \\ alguns projetos e facilitar algumas \\ produções, as leis de incentivo \\ cultural de certa forma acomodaram \\ os empreendedores culturais, bem \\ como a classe artística.
}

incentivo e verbas de marketing direto, esses empreendedores passaram a identificar oportunidades com potencial de crescimento.

\section{O PARADOXO NA ÁREA ARTÍSTICA}

Como conectar empreendedorismo e arte/cultura? De acordo com artigo publicado no site Cultural Weekly, artistas são, a priori, empreendedores, por três razões:

a. Enxergam "algo mais" além do arco-íris: vão muito além do que a maioria das pessoas, que não consegue sair do primeiro degrau;

b. São executores: vão e fazem acontecer. Tiram o sonho do papel e o tornam realidade;

c. Sempre querem modificar ou melhorar algo: podem entregar porque o prazo acabou, mas o processo continuará sempre em movimento. 


\section{A CADEIA DA INDÚSTRIA CRIATIVA NO BRASIL}

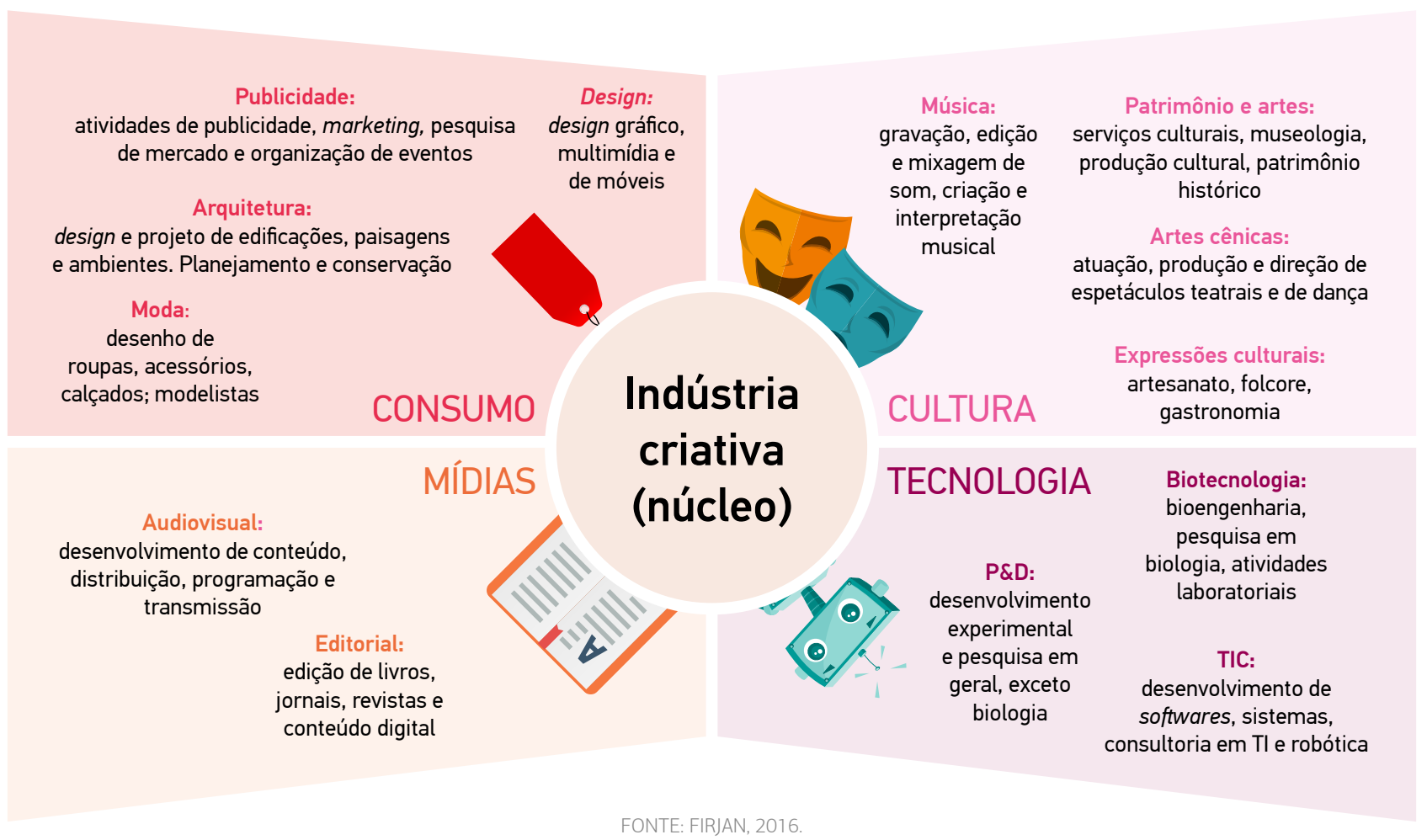

Apesar desses comportamentos similares, um aspecto central dificulta aos artistas enxergarem-se como empreendedores: eles questionam se é legítimo utilizar arte e cultura para buscar lucro. A arte seria governada por princípios diferentes dos da economia de mercado. Um projeto artístico-cultural correria então o risco de perder sua identidade se direcionado pelos interesses de produtores e investidores.

No setor artístico-cultural do Brasil, as organizações estruturadas em moldes empresariais não são o modelo predominante. No país, prevalecem organizações culturais sem fins lucrativos e pequenos grupos de artistas e produtores que, muitas vezes, se organizam de modo voluntário e temporário para um espetáculo ou uma produção cultural. Sua sustentação é precária, por meio de doações, verbas públicas ou privadas. Muitas vezes, o trabalho não é remunerado.

Há um claro paradoxo na área. Ainda que exista um interesse comum para todos os envolvidos em uma produção artística (como o sucesso de público e crítica ou o desejo de ver a casa lotada), há também interesses que são conflitantes; por exemplo, de um produtor que busca ganhar mais e minimizar os custos versus um diretor artístico ou artistas que optam por materiais mais caros em nome da qualidade.

\section{OS EMPREENDEDORES EM CULTURA}

Assim, esse mercado é bastante dependente de políticas culturais públicas e privadas para a área, como as leis de incentivo fiscal Rouanet (IR - federal), PROAC (ICMS estadual) e PRO-MAC (IPTU e ISS - municipal). O número de empresas privadas que passaram a usar o investimento na área cultural como ferramenta de marketing, para a divulgação de sua marca e seus produtos, também aumentou significativamente. Em geral, as produções culturais podem ter recursos de diversas fontes, como leis de incentivo, verba de marketing direto, outras formas de editais, convênios, crowdfunding, permutas, além da bilheteria e venda de produtos.

Essas mudanças têm como consequência o aumento da demanda por gestores. $\mathrm{O}$ empreendedor artístico-cultural é o responsável pela busca de recursos financeiros e pela 
formulação das estratégias para o desenvolvimento do negócio, sempre procurando oportunidades, alguma inovação e crescimento. É também aquele que deve lidar com todos os stakeholders envolvidos: artistas, criadores, produtores, técnicos, agências de fomento, comunidades. Hoje, um bom empreendedor cultural transita muito bem em todas essas esferas e tem boa conexão comercial. Além disso, busca uma rede de empresas que dão o suporte necessário para a captação por intermédio de leis de incentivo, por meio de contrapartidas que funcionem e interessem para a empresa patrocinadora. A questão do relacionamento é fundamental: é comum um empreendedor ter sempre o mesmo patrocinador para várias produções, bem como o mesmo elenco e a mesma equipe.

\section{ARTE, CULTURA E FUTURO}

Empreender na arte/cultura no Brasil não é uma tarefa fácil. A questão maior é o risco envolvido, inerente ao ato de empreender. Há dois pontos nevrálgicos: a falta de previsibilidade e o alto risco nesta área. Nas grandes produções, nunca se sabe ao certo qual será a reação da crítica e a aceitação do público. $O$ custo de manutenção mensal de um espetáculo de grande porte (um musical, por exemplo) é altíssimo. Somadas aos recursos oriundos das leis governamentais de incentivo, as receitas de bilheteria pagas pelo público nem sempre cobrem todas as despesas. Para fazê-lo, e ainda remunerar investidores e produtores, o negócio, para ser viável, depende da verticalização, ou seja, do ganho em toda a cadeia - alimentos, bebidas, lojinha de produtos do espetáculo, etc. Além da incerteza de sucesso e dos custos altos, um projeto artístico-cultural tem duração definida e limitada, na maior parte das vezes. Há um prazo que também limita as possibilidades de ganhos.

É necessário repensar os modelos de negócios atualmente utilizados. Nos espetáculos de teatro musical, enormes produções são feitas a um custo altíssimo ( $\mathrm{R} \$ 5, \mathrm{R} \$ 10$ ou $\mathrm{R} \$ 20$ milhões). Muitas vezes, ficam pouco tempo em cartaz por diversas razões: falta público, dinheiro mal administrado, falta de teatros e espaços, desorganização, falta de planejamento ou interferências políticas.

As políticas culturais também têm se mostrado ineficientes para o desenvolvimento do empreendedorismo artístico. Ainda que possam viabilizar alguns projetos e facilitar algumas produções, essas leis de certa forma acomodaram os empreendedores culturais, bem como a classe artística. Tornaram-nos, de algum modo, dependentes de recursos públicos. Considerando ainda que falta no Brasil uma política cultural consistente e perene, os participantes da
De um lado, empreendimentos culturais com fins lucrativos devem ir atrás de inovações e novos modelos de negócios. Do outro, é preciso implementar políticas públicas para que atividades que possuam função social possam continuar preservando a arte e a cultura do país.

indústria ficam suscetíveis às reduções de recursos em períodos de crise.

$\mathrm{O}$ ecossistema do empreendedorismo cultural se desenvolveu nos últimos anos: temos produções de excelente qualidade e os artistas estão cada vez mais capacitados. Mas ainda há muito a ser feito. É preciso mudar a mentalidade e o modus operandi dos empreendedores culturais e dos artistas. É necessário desenvolver o espírito empreendedor, a busca pela inovação e as novas oportunidades. É preciso quebrar a dependência de grandes projetos e verbas de incentivo, gerada pelo modelo atual. Empreendedores artístico-culturais não podem depender de leis de incentivo somente. Estas devem ser uma das possibilidades para viabilizar os projetos, pois é papel do empreendedor cultural sempre buscar outras possibilidades e inovar.

Por outro lado, é preciso desenvolver, nas empresas e nos cidadãos brasileiros em geral, uma cultura de investimento e doação para atividades artísticas, bem como implementar políticas públicas que criem condições mínimas para que atividades artísticas e culturais cumpram a sua função social. Há museus, companhias de dança, teatro e orquestras que são intrinsecamente deficitários, mas devem ter condições para continuar desenvolvendo projetos e inovar, preservando a arte e a cultura do nosso país.

\footnotetext{
PARA SABER MAIS:

Pedro Bendassolli, Thomaz Wood Jr., Charles Kirschbaum e Miguel Pina e Cunha. Indústrias criativas no Brasil: cinema, TV, teatro, música, artesanato, software, 2009. Candace Jones, Mark Lorenzen e Jonathan Sapsed. The Oxford Handbook of Creative Industries, 2015.

FIRJAN. Mapeamento da Indústria Criativa no Brasil, 2016

Tânia Limeira. Empreendedor Cultural: Perfil e Formação Profissional, IV Enecult, UFBA,2008.
}

ADRIANA MIGUEL VENTURA > Professora da FGV EAESP e diretora do Espaço 10×21- Espaço multicultural destinado a atividades artísticas e culturais > adriana.ventura@fgv.br 